\title{
Explaining Crime and Criminal Careers: the DEA Model of Situational Action Theory
}

\section{Per-Olof H. Wikström ${ }^{1}$}

Received: 18 February 2019 / Accepted: 29 April 2019 /

Published online: 6 June 2019

(C) The Author(s) 2019

\section{Abstract}

Purpose The purpose of this paper is to outline Situational Action Theory (SAT) and its Developmental Ecological Action Model (DEA model) as applied to the explanation of criminal careers. The DEA model of SAT was first presented by Wikström in 2005, [34]), and subsequently refined in Wikström and Treiber in 2018, [43]), and is further elaborated in this paper.

Methods This paper provides a theoretical analysis of the role of crime causation in the explanation of criminal careers and pathways in crime. The central argument is that if we want to explain stability and change in people's crime involvement we first have to understand what factors and processes move people to commit acts of crime. Only then can we adequately assess what factors and processes are involved in the explanation of criminal careers and people's differential pathways (trajectories) in crime.

Results The DEA model of SAT address some of the main limitations of current dominant explanatory approaches in Developmental and Life-Course (DLC) Criminology [39], and champions a general, dynamic and mechanism-based account of the causes of crime [38], and the drivers of criminal careers [47]. It integrates and extends key insights from two great but poorly amalgamated traditions in the study of crime and its causes: the individual/developmental and ecological/environmental traditions. It provides a new approach to the study and explanation of crime and criminal careers with implications for how we approach the problem of crime prevention policy and practise.

Keywords Crime · Criminal careers · Causes · Causal mechanisms · Situational action theory . The developmental ecological action model

Per-Olof H. Wikström

pow20@cam.ac.uk

1 Institute of Criminology, University of Cambridge, Sidgwick Avenue, Cambridge CB3 9DA, UK 
A criminal career is made up of a series of crime events occurring over some period of time at some (typically) unequal interval. How do we explain people's criminal careers and their different pathways in crime involvement? I submit that without first understanding the causes of crime events it is not possible to adequately explain people's criminal careers. If we do not know why people commit acts of crime how would we know why they embark on a criminal career (repeated offending over some time period)? And how would we know why people's crime involvement change over the life course? Effectively addressing questions of onset, duration and desistance in crime involvement requires knowledge about what moves people to engage in acts of crime. Without such knowledge, it is difficult to identify with any certainty what changes in what personal and environmental factors are causally relevant and what processes may be the drivers of stability and change in these personal and environmental factors.

\section{Developmental and Life-Course Criminology and Its Current Limitations}

Developmental and life-course criminology (DLC criminology) has emerged as a prominent and important perspective in the study of crime and its causes [10], some even argue that 'life-course criminology is criminology' [7:310]. At the core of DLC criminology is the study of criminal careers and their characteristics. A criminal career has been defined as the 'characterization of the longitudinal sequence of crimes committed by an individual offender' [2:12] and the main objective of developmental criminology has been stated as the study of 'temporal within-individual changes in offending' [16:117].

People vary in their crime involvement, and among those involved in repeated offending, they vary in their pathways in crime. Pathways have been defined as "a common pattern of development shared by a group of individuals, which is distinct from the behavioural development experienced by other groups of individuals" [19:98]. Group-based trajectory modelling (e.g. [28]) has been employed to identify the number of pathways in crime (i.e. the identification of groups of people with similar trajectories in crime involvement). Typically, this research comes up with 3-4 main groups (e.g. [13:485]), ${ }^{1}$ although there are trajectory studies that identify more groups than so. The most well-known and well-developed criminal career pathways classification is undoubtedly Terrie Moffitt's [23, 24] 'developmental taxonomy' that suggests two main groups of criminal careers; adolescence-limited and life-course persistent offenders. ${ }^{2}$ The great advantage of Moffitt's approach is that she takes seriously the role of the person-environment interaction. However, as most DLC theories, ${ }^{3}$ her explanation focuses on detailing the sources of crime propensity rather than the causes of crime

\footnotetext{
${ }^{1}$ In which the largest group typically consists of those who commit no or only occasional crimes in the period of study. Differences in the number of identified groups appear partly related to what kind of data are used (e.g. self-reported or official recorded crime) and the age period covered by the study.

${ }^{2}$ While the existence of an adolescence-limited group of offenders in Western developed countries seems largely uncontroversial, the existence of a life-course persistent group has generated more disagreements (e.g. [30]).

${ }^{3}$ David Farrington and colleagues observes that "Most theories try to explain the development of offenders, but some (e.g. the integrated cognitive antisocial potential theory and the situational action theory) also try to explain the occurrence of offences" [12:750].
} 
events, and consequently, it lacks any explicit action theory (linking propensity to action).

DLC criminology has made a significant contribution to criminology as regards advancing our knowledge of patterns in people's crime involvement and their changes over the life course, particularly from childhood to young adulthood ${ }^{4}$ (e.g. $[11,14,15$, $18,20,21,22,29,32,33,48]$ ). However, it has been less successful in terms of developing satisfactory explanations of the drivers of people's criminal careers and different pathways in crime [39]. I suggest that one prime reason for this is that many DLC researchers tend to adopt a public health perspective, with its strong focus on identifying risk (and protective) ${ }^{5}$ factors (i.e. predictors) often with problematic causal status. The problem is well illustrated by Joseph Murray and David Farrington ([26]:639, my emphasis) in the following quote ${ }^{6}$;

'Offenders differ significantly from nonoffenders in many respects, including impulsiveness, low IQ, low school achievement, poor parental supervision, punitive or erratic parental discipline, cold parental attitude, child physical abuse, parental conflict, disrupted families, antisocial parents, large family size, low family income, antisocial peers, high delinquency rate schools, and high crime neighbourhoods. Further, the probability of an adverse outcome such as CD or delinquency increases with the number of risk factors. While the precise causal chains that link these factors with antisocial behaviour, and the ways in which these factors have independent, interactive, or sequential effects, are not well understood, it is clear that numerous replicable risk factors have been identified'

A risk factor is commonly defined as a predictor; a factor (variable) that is statistically significantly associated with and precedes the outcome (e.g. [6, 17]). Prediction (a forecast of an outcome based on a regularly occurring association between and time ordering of the predictor and the outcome) is not the same as causation. It is only one criterion for establishing causation. To distinguish between 'causes' and 'predictors' we also need to identify a plausible process that connects the putative cause and the effect and that produces the effect. In other words, we need to make a strong and credible argument for why and how the putative cause would produce the effect in question. For example, is there any plausible causal process that would explain why 'a large family size' would make anyone throw acid in another person's face, sexually abuse a child or break into another person's house? If there is no probable causal process linking a predictor with the outcome in question, it is unlikely we are dealing with a causal relationship $^{7}$ (see further, [37]). It is safe to assume that most identified 'risk factors' (crime predictors) are markers and symptoms rather than causes.

\footnotetext{
${ }^{4}$ Few longitudinal studies of crime go beyond the age of 30 .

${ }^{5}$ The difference between risk and protective factors is essentially that the former is supposed to increase and the latter to decrease the risk of crime involvement.

${ }^{6} \mathrm{CD}$ in the quote refers to "conduct disorders".

${ }^{7}$ The safest way to establish causation is through experimentation but this is rarely a feasible option in DLC research. The common idea, that 'controlling for other variables' helps establish causation (e.g. [27]:12-13), is largely misguided. It should also be noted that establishing causal relevance through experimentation does not in itself provide explanation, i.e. provide any understanding of the process by which the putative cause produces the effect (on the problem of prediction, causation and explanation, see further, [37]). Knowing why and how a cause produces an effect may be crucial for developing effective policy and prevention.
} 
The problem of distinguishing between causes and predictors is a problem that has been acknowledged by many leading DLC scholars. Rolf Loeber observes that 'the causal relationship between the risk factor and the outcome is often far from clear, and may even be absent' [17:4]. David Farrington recognises that 'a major problem with the risk factor paradigm is to determine which risk factors are causes and which are merely markers or correlated with causes' [9:7]. This problem is particularly pertinent when a risk and protective factor approach is applied to policy and prevention since there are good reasons to believe that most identified risk and protective factors lack causal efficacy (i.e. are only markers or symptoms). Addressing non-causal factors in crime prevention policy and practise is obviously only a waste of time and money.

The confusion often caused by the concept of risk factor is well illustrated by the fact that it is not uncommon to come across the argument that risk factors are not causes of crime but that reducing risk factors would reduce crime, which, of course, does not make much sense. It is important to realise that all statements that include concepts such as 'influence', 'effect', 'increase', 'reduction' or 'change' imply the supposition of some causal efficacy. Moreover, all claims that removing or altering some factor would prevent an outcome (such as an act of crime) imply the assumption that the factor has some causal efficacy relating to the outcome.

One intriguing but unexplained finding of DLC criminology (and risk factor research more generally ${ }^{8}$ ) is the common result that the more risk factors a person displays, the more likely she or he is to also display the outcome (e.g. crime involvement). This is generally discussed as the phenomenon of 'cumulative risk' [22:122, 31] and has sometimes, within the policy approach of risk-focused prevention, led to the mistaken idea that the more risk factors we can eliminate or counteract, the stronger the preventive effect on the outcome becomes. However, better prediction does not necessarily equal stronger causation. In fact, strong (even perfect) prediction may not imply any causation at all, ${ }^{9}$ and without causation there is no possibility of prevention. ${ }^{10}$ Cumulative risk is unlikely to equal cumulative causation.

To advance our knowledge about criminal careers and their causes (and its prevention), we need to move beyond a risk and protective factor approach to explanation (and as a basis for devising prevention policy and practise) and instead focus on the identification of which triggers and processes are causally relevant and important in explaining criminal careers and different pathways in crime. I submit that to do this we need (i) an adequate action theory that explains what moves people to engage in acts of crime, (ii) an ecological approach that identifies the role of personal and environmental factors and their interaction in this process, and, on this basis, (iii) an identification and explication of the processes that drive stability and change in causally effective crime relevant personal (propensity) and environmental (inducement) factors.

\footnotetext{
${ }^{8}$ Gary Evans and colleagues observes that 'One of the primary limitations of CR is the lack of theoretical explanation for its predictive power. At present, there is no theoretically compelling rationale to account for the superior predictive power of multiple versus singular risk factor exposures on child outcomes' [8:1380]. CR in the quote stands for cumulative risk.

${ }^{9}$ Causation requires prediction, but prediction is no evidence of causation.

${ }^{10}$ To prevent something is to make something not happen that otherwise would have happened.
} 


\section{Advancing DLC Criminology: the DEA Model of SAT}

The developmental ecological action model (the DEA model) of situational action theory (SAT) is aimed at helping to overcome some common problems in DLC criminology (e.g. the lack of action theory, the neglect of properly addressing the role of the personenvironment interaction in crime causation and the confusion of causes and correlates). A regular DLC argument is that the causes of crime (typically conceptualised as risk and protective factors) are different for different people, at different stages of a criminal career and in different developmental phases/ages (see, e.g. [25]). SAT on the other hand proposes a general theory of crime causation arguing that the causes of crime are the same for all people, at all ages and at all stages of a criminal career [38].

The DEA model of SAT offers an ecological-action theoretical perspective in the study and explanation of the development and life course of people's criminal careers. Its analysis of people's pathways in crime and their characteristics is based on the following premises:

1. The basis for explaining people's criminal careers is the understanding of what moves people to engage in acts of crime (action theory).

2. Acts of crime are an outcome of the interaction of people's crime propensity (dependent on their personal morals and ability to exercise self-control) and criminogenic exposure (dependent on the moral context of the opportunities and frictions they encounter in the setting in which they take part) (ecological perspective).

3. Stability and change in people's crime involvement (and differential pathways in crime) is a consequence of (patterns of) stability and change in people's crime propensity and/or criminogenic exposure (development and change).

4. The main drivers of stability and change in people's crime propensity are the psychosocial processes of moral education and cognitive nurturing and the main drivers of stability and change in people's criminogenic exposure are the socioecological processes of social and self-selection (drivers).

5. The content and efficacy of the psychosocial and socioecological explanatory processes involved are context dependent, that is, dependent on relevant cultural (rule-based) and structural (resource distribution-based) features of the society and its constituent parts in which these processes occur (context).

\section{Why Crime Happens}

At the core of any proper explanation of human action (such as acts of crime) is an adequate action theory that specifies what moves people to action. Crimes are actions that breaches rules of conduct stated in law. As such they are no different from rule breakings more generally. Situational action theory (SAT) maintains that people are the source of their actions but that the causes of their actions (such as acts of crime) are situational [35, 36, 38, 40, 45].

SAT explains people's acts of crime and their rule breakings more generally, as a consequence of how they perceive their action alternatives and make their choices in response to the motivators (temptations, provocations) they experience in particular 
settings. ${ }^{11}$ SAT proposes that people essentially commit acts of crime because they see them as a viable and acceptable action alternative in the circumstance (and there is no relevant or strong enough deterrent) or they fail to act in accordance with their own personal morals (i.e. fail to exercise self-control) when externally pressured to act otherwise.

Whether or not an act of crime is seen and chosen as an action alternative in relation to a specific motivator is the outcome of a perception-choice process initiated and guided by the interaction of the person's crime propensities and the setting's criminogenic inducements (Fig. 1). This process may be more or less automated (ranging from predominantly habitual to predominantly deliberative) depending on the nature of the circumstances (see further, e.g. [35]:97-104). The key proposed elements of the perception-choice process are motivators (goal-directed attention), the moral filter (which provides action alternatives in relation to motivators in particular circumstances) and controls (self-control and deterrence which affects non-habitual processes of choice when people deliberate between action alternatives). For details of the key suggested elements of the perception-choice process and their role in this process, see, e.g. Wikström [38].

SAT stipulates that people's crime propensity (their tendency to see and choose crime as an action alternative in particular circumstances) is dependent on their lawrelevant personal morals and ability to exercise self-control. ${ }^{12}$ SAT define a person's personal morals as her or his value-based and emotionally grounded views about what is the right or wrong thing to do or not to do in particular circumstances. A person's ability to exercise self-control is her or his ability to act in accordance with her or his own personal morals when externally pressured to act otherwise. The theory further maintains that a setting's criminogeneity (its tendency to encourage [or not discourage] particular kinds of crime) is reliant on the moral context applicable to the opportunities it provides and the frictions it creates. The moral context is the moral norms (perceived shared rules of conduct and their degree of homogeneity), and the level and efficacy of their enforcement, relevant to a settings opportunities and frictions.

People are different (have different crime propensities) and so are environments (have different criminogenic inducements). Whether or not a crime will happen depends on what kind of person is in what kind of setting. A person's particular crime propensities are activated by a setting's specific criminogenic inducements and a setting's particular criminogenic inducements are made relevant by a person's specific crime propensities. In other words, it is all about interactions.

The proposed nature of the propensity-exposure interaction is that people with low crime propensity (as a consequence of a strong law relevant personal morality and a strong ability to exercise self-control) are largely resistant to a setting's criminogenic

\footnotetext{
${ }^{11}$ SAT differentiates between place (a location and its immediate environment) and setting (what a person in a particular place experience with her or his senses at a particular moment in time). The latter emphasises the importance of selective perception, different people in the same place may pay attention to different things depending on their experiences, preferences and skills. However, in this paper, this distinction is of no great importance for the arguments forwarded so I will make no particular point of distinguishing between place and setting, using them interchangeably as referring to the micro-environments in which people take part.

12 Please note that a person's crime propensity is not their personal morals and ability to exercise self-control but that these are the two main sources of people's crime propensity (i.e., their tendency to see and choose crime as an action alternative).
} 


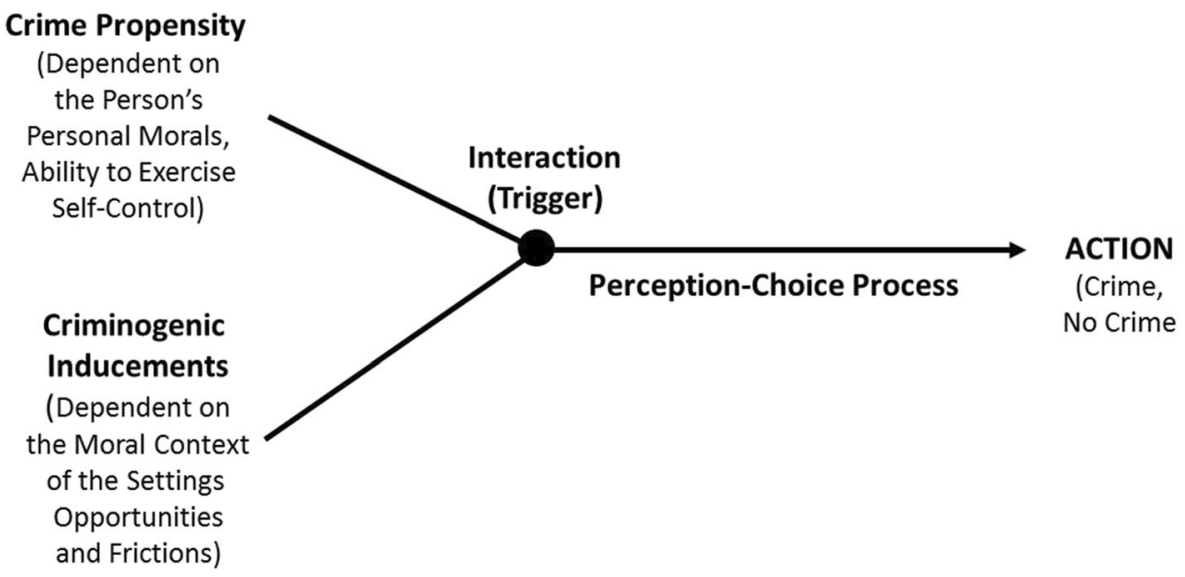

Fig. 1 The causes of crime according to SAT

inducements while people with a stronger crime propensity are vulnerable to such inducements, and increasingly so the stronger their crime propensity is (for empirical support of this assertion, see [46]). People vary in their general crime propensity (i.e. in the range of circumstances in which they may see and chose crime as an option). People also vary in their crime-specific crime propensities (e.g., for some, shoplifting may be an acceptable action alternative while threatening another person with violence to get their possessions may not). A highly crime-prone person is one who tends to see and chose crime as a viable and acceptable action alternative in a wide range of circumstances. $^{13}$

\section{Explaining Criminal Careers}

Understanding criminal careers (including criminal career aspects such as onset, duration and desistence) is fundamentally a question of understanding what propels stability and change in people's crime involvement.

If people's acts of crime are an outcome of the interaction between their crime propensity (dependent on their law-relevant personal morals and ability to exercise selfcontrol) and their exposure to criminogenic settings (i.e. places whose moral context encourage [or do not discourage] crime as a response to its opportunities and frictions), it is a reasonable hypothesis that stability and change in people's crime involvement is a consequence of stability and change in their crime propensity and criminogenic exposure. That is so, because a person's crime propensity and criminogenic exposure constitutes the input to the perception-choice process that ultimately determines whether or not a crime will happen (Fig. 1). Alter the input and the behaviour will change.

Changes in a person's personal morals (content) or ability to exercise self-control (cognitive machinery) affecting her or his crime propensity, and/or changes in the moral contexts she or he takes part in affecting her or his level of criminogenic exposure, will

\footnotetext{
${ }^{13}$ When analysing specific types of crime, e.g. crimes of violence, a highly violent prone person is one that tends to see and choose acts of violence as a viable and acceptable action alternative in a wide range of circumstances.
} 
change her or his likelihood of engaging in acts of crime. Let me give two examples. A lowered crime propensity (e.g. as a consequence of the development of a stronger lawrelevant personal morality or a stronger ability to exercise self-control) may make people more resistant to settings' criminogenic inducement (i.e. make them less likely to see and chose crime as an action alternative). A decrease in the time a person spends in criminogenic settings may reduce their overall crime involvement regardless of any changes in her or his crime propensities.

Different combinations of continuity and change in people's crime propensity and criminogenic exposure will cause different patterns of continuity and change in their crime involvement and its nature (e.g. as captured by criminal career concepts such as duration, escalation and desistence). If stability and change in people's crime propensity and criminogenic exposure fundamentally explains stability and change in their crime involvement, the key question then becomes, what drives stability and change in people's crime propensity and criminogenic exposure?

\section{The Drivers of Stability and Change: the DEA Model of Situational Action Theory}

According to the DEA model of SAT, what largely drives stability and change in people's crime propensity are psychosocial processes of moral education and cognitive nurturing and what principally drives stability and change in people's criminogenic exposure are socioecological processes of social and self-selection (Fig. 2). ${ }^{14}$

These are lifelong processes (causal chains) ${ }^{15}$ in which current states (propensities, exposures) are a result of past developments (influences) at the same time as they set the stage for future developments (influences). They do not occur in a social vacuum but are dependent for their content and efficacy on the wider social context in which they occur (i.e. the cultural [rule-based] and structural [resource-distribution-based] characteristics of society and its constituent parts). Changes in the cultural and structural context in which these processes take place may modify their content and affect their efficacy. The basic processes are not unrelated because the socioecological processes influence not only people's exposures to criminogenic settings ${ }^{16}$ but also their exposures to (other) settings of relevance to the content and efficacy of their moral education and cognitive nurturing.

\section{Psychosocial Processes}

The basic proposition is that stability or change in a person's crime propensity between two time points essentially is a result of stability or change in processes of moral education and/or cognitive nurturing between the same two time points.

\footnotetext{
${ }_{14}$ These processes are also referred to as the 'causes of the causes' in the SAT explanatory framework.

15 Birth (or in some aspects even pre-birth) is the natural starting point and death the natural end point for these processes.

${ }^{16}$ People's experiences of criminogenic settings are not only a question of their level of criminogenic inducement but they may also form an important part of their crime relevant moral education (as discussed further below).
} 
Cultural (rule-based) and Structural (resource-distribution-based) context

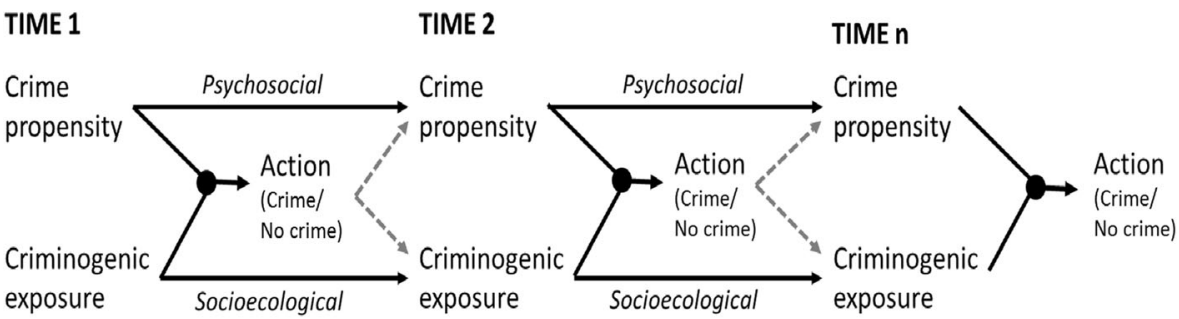

Fig. 2 The drivers of stability and change in people's crime involvement according to the DEA model of SAT

Moral education refers to the continuous learning and evaluation process by which people come to adopt, modify and change value-based and emotionally grounded rules of conduct about what is the right or wrong thing to do or not to do in particular circumstances. The central (sub) mechanisms of moral education are instruction (written or verbal), observation of others' actions, their consequences and the reactions they evoke and trial and error (personal 'experimentation', trying out actions and experiencing their consequences and others' reactions). Of special interest when analysing the emergence and changes in people's crime propensity is the role in moral education of the law and law making (e.g. its rule guidance) and the operations of the criminal justice system (e.g. its general and specific deterrent qualities). People are not passive recipients of moral experiences but they actively evaluate (and re-evaluate) those experiences against the background of their previously acquired personal morals and cognitive abilities. Changes in people's personal morals are typically gradual rather than instant. However, moral transformations may be accelerated in certain developmental phases or as a response to significant life events or social changes.

Cognitive nurturing refers to the experiential processes (limited by a person's neurological constitution and baseline capacities) that positively influence neurocognitive capacities and their expression. The training of cognitive skills (executive functions) is important for strengthening people's ability to exercise self-control, but may also be relevant for their ability to acquire, understand and apply rules of conduct. Changes in crime relevant cognitive skills may also be affected by biological processes of maturation and ageing and a consequence of (brain) injury and ill health (for further details and discussion, see [43]:284-285). Changes in people's cognitive abilities are typically slow but heighten at specific developmental phases, ${ }^{17}$ such as in childhood, and may be instant in certain cases of injury or illness.

\section{Socioecological Processes}

The basic proposition is that stability or change in a person's criminogenic exposure between two time points essentially is a result of stability or change in processes of social selection and self-selection between the same two time points.

\footnotetext{
${ }^{17}$ Benjamin Bloom has convincingly argued that "variations in the environment have the greatest quantitative effect on a characteristic at its most rapid period of change and least effect on the characteristic during the least rapid period of change' [1: vii].
} 
Social selection refers to the cultural (rule-based) and structural (resource-distributionbased) conditions in a jurisdiction (e.g. a nation or a city) affecting its member's differential exposure to particular kinds of settings (including criminogenic settings). It is the rule- and resource-distribution-based circumstances that enable (encourage or compel) or restrict (discourage or bar) particular kinds of people from taking part in particular kinds of time- and place-based activities. ${ }^{18}$ Social selection has a generalised influence on what kinds of settings different social groups of people will take part in (e.g. some social categories are more likely to have a higher exposure to criminogenic settings than others). Depending on what social categories people belong to (e.g. by gender, age, ethnicity and social class), particular cultural and structural aspects of society are more relevant than others in shaping and forming their day-to-day life. To comprehend the role in the explanation of crime of such things as societal inequality and segregation requires an understanding of how processes of social selection help create a differential exposure to the settings in which people act (and, over the longer term, develop). Changes in processes of social selection, typically as a result of political, economic and technological changes, are typically gradual but can in more extreme cases be fast or even instant (such as in times of sudden or rapid social change).

Self-selection refers to the person's preference and agency-based choices of taking part in particular kinds of settings within the constraints of the forces of social selection. People vary in their activity preferences depending on their previous life history experiences (i.e. how these experiences have helped form and shape their desires and wants). They also vary in their agency (their powers to make things happen) affecting their capacity to materialise their preferences. Agency is partly age-related. For example, as a new born or toddler, humans have very limited, if any, agency. With increasing age people's agency tends to increase. However, it is highly variable among people depending on their human, financial and social capitals. ${ }^{19}$ Some people have much more agency than others.

The combination of processes of social and self-selection determine the content of a person's daily life. The particular configuration of the kind and nature of the settings (e.g. family, school, work and leisure settings and their characteristics) a person typically takes part in may be referred to as her or his activity field [44]. People vary in their activity fields, and in the extent to which they include criminogenic settings. A person's activity field, the system of settings in which she or he takes part, constitutes their personal social context (embedded in and indirectly dependent on the larger social context of the society in which she or he lives and operates).

\section{The Role of the Crime Event in Processes of Moral Education and Self-Selection}

The crime event naturally has a central role in any analysis of criminal careers since a criminal career constitutes a series of crime events. The fact that past crime regularly is

\footnotetext{
${ }_{18}$ For example, at certain ages, people are expected to attend school, to get a job and support themselves etc.

${ }^{19}$ Human capital refers to things such as skills and experiences, while social capital refers to the access to resourceful social networks.
} 
found to be a good predictor of future crimes does not imply that the former causes the latter. $^{20}$ Since the causes of crime are situational $[35,38]$, there is no direct causal link between one crime event and the next. ${ }^{21}$ However, people's past crimes may indirectly influence their current crimes through the potential impact on the psychosocial and socioecological processes of relevance for the development and change of their crime propensity and criminogenic exposure (as indicated by the dotted lines in Fig. 2). The DEA model of SAT proposes specifically that people's experiences of taking part in a crime event (and repeated crime events) may influence (a) their future crime propensity by influencing the psychosocial processes of moral education and (b) their future criminogenic exposure by impacting the socioecological process of self-selection.

Crime events (as moral experiences) are an essential part of the process of law-relevant moral education. Depending on the reasons for why a person engages in an act of crime, its outcomes and its consequences for the actor and others, taking part in a crime event may lead to changes in a person's personal morals. For example, the moral experience of a crime event may result in a re-evaluation of certain action alternatives in particular circumstances that, depending on its direction, may increase or decrease the person's crime propensity. Moreover, repeated experiences of ('successfully') carrying out certain acts of crime in particular circumstances may in some cases result in the 'normalisation' of such responses or even create a habituation (i.e. cause the seeing and choosing of crime as an action alternative in certain circumstances to become an automated response). The potential influence on a person's future law-relevant personal morals from the moral experience of committing a particular act of crime may be seen as part of the earlier mentioned 'trial and error' ('personal experimentation') sub-mechanism of moral education.

The experience of crime events may also influence people's future inclinations to take part in or shun particular kinds of settings (i.e. influence their self-selection). For example, it may lead to them increasingly seek out or tend to avoid criminogenic settings, hence, affecting their future criminogenic exposure. For example, positive experiences (of whatever kind) of engaging in crime events may encourage a person to become more immersed in a 'criminal lifestyle' causing an amplified criminogenic exposure, e.g. as a consequence of increased 'pre-planning' and 'search behaviour'. On the other hand, increased negative experiences of different kinds from a 'life of crime' may lead to the development of an ambition to actively avoid taking part in settings that the actor believes risk getting her or him into trouble with the law or otherwise (see, e.g. [3]).

In addition to the potential impact of carrying out acts of crime, experiences of being a victim of crime, or witnessing a crime event, (or repeated such experiences) may also have some significant influences on a person's future law-relevant personal morals (i.e. increase or decrease their crime propensity) and tendency to seek out or avoid criminogenic settings (e.g. avoiding certain places through increased fear of victimisation).

\footnotetext{
${ }^{20}$ Correlation is not causation.

${ }^{21}$ Please note that a crime event can involve several types of crimes (law violations), e.g. an attack on another person can involve illegal threats, violence and vandalism (a person may smash a bar chair on the head of another person at the same time as threatening to kill his family).
} 


\section{Drivers of Criminal Careers and Their Context Dependency}

Psychosocial processes influencing people's crime propensity and socioecological processes affecting people's criminogenic exposure do not happen in a social vacuum. They are dependent for their content and efficacy on the social context ${ }^{22}$ in which they occur (i.e. the cultural [rule-based] and structural [resource-distribution-based] characteristics of society and its constituent parts) (Fig. 2).

The process of moral education (i.e. the process of acquiring, modifying and changing personal morals) is dependent on the moral contents of the social context in which it takes place because it provides the input to the process. What moral teachings and experiences people comes across (through instruction, observation and 'trial and error') and the efficacy of their communication is contingent upon their day-to-day activities and interactions with relevant others (e.g. parents, teachers, peers, partners, and work mates) and encounters with various forms of written, oral and visual media. The specific configuration of activities, relevant others and media exposures that a particular person encounters in their everyday life (its content and efficacy) constitutes the (immediate) social context (the activity field) in which her or his moral education takes place (which, in turn, is embedded in and feed upon the wider moral climate of the society at large and its homogeneity).

The content and efficacy of the process of cognitive nurturing is dependent on the extent to which people's day-to-day experiences (the activities they take part in and the people they interact with) encourage and provide opportunities for proficient training of their cognitive capacities, for example, by exercising problem-solving, patience, concentration and restraint (see further, [43]:285). For people with cognitive impairments, the access to and quality of support and care (e.g. through the health services) may be of central importance. A person's particular configuration of the activities she or he takes part in and the kinds of people she or he interacts with constitutes the key elements of the social context in which her or his cognitive nurturing occurs. The wider society and its constituent parts may be more or less well organised and competent in terms of its key relevant social institutions and practises as regards their encouragement and support of particular social groups and individuals cognitive nurturing.

Each society is a result of historical processes of social emergence, ${ }^{23}$ creating particular patterns of spatial and temporal population and activity differentiation. These are manifested in a mosaic of rule- and resource-based settings and their specific characteristics (including their levels of criminogeneity) that constitutes the wider social context in which processes of social selection operate and on which they are reliant. Depending on the specific cultural (rule-based) and structural (resource-distributionbased) context of a society, processes of social selection will have particular outcomes (e.g., in terms of their influences on different population segments' and ages' configurations of exposures to criminogenic and other settings). Changes in a society's cultural and structural features may change the operations and consequences of social

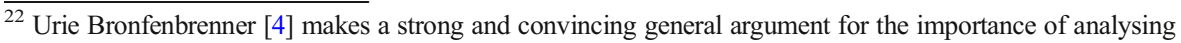
human development in context, and the importance of considering how the immediate context that directly affects people's development is embedded in and dependent on the wider social contexts.

${ }^{23}$ Social emergence refers to the process by which a society become as it is, dependent on complex historical processes, including political, economic and technological progression and change.
} 
selection, generally and for specific social categories (e.g. by gender, age, ethnicity and social class), with implications for their exposure to criminogenic and other settings.

However, and as discussed earlier, people are not passive recipients of influences from social forces but actively navigate their lives within the constraints of social selection. Some social contexts are more constraining than others, generally, or for particular groups of people (i.e. leaving them less room for manoeuvre). In other words, the efficacy of self-selection is context dependent and may vary between different social categories (e.g. by gender, age, ethnicity and social class ${ }^{24}$ ).

\section{Key Dimensions of Criminal Careers and Their Explanation}

The DEA model of SAT offers a parsimonious way of explaining criminal careers, their characteristics and people's different pathways in crime: Stability and changes in people's crime involvement (prevalence and frequency) reflects stability and changes in their crime propensity and exposure to criminogenic settings. This is simply so because crime events are an outcome of the interaction between a person's crime propensity and exposures to criminogenic settings, and changes in a person's crime propensity and/or her or his exposure to criminogenic settings will change the number of criminogenic interactions she or he encounters and thereby affect her or his crime involvement. A criminogenic interaction occurs when a person with a sufficiently strong crime propensity encounter a setting with a criminogenic inducement that is sufficiently strong to activate her or his crime propensity. ${ }^{25}$ Different combinations of continuity and change in people's crime propensity and criminogenic exposure will cause different patterns of continuity and change in their crime involvement and its nature.

The DEA model of SAT proposes that all key descriptive criminal career parameters (see e.g. [16]), for example, those that refer to duration (onset and termination), regularity of offending (e.g., acceleration and de-acceleration) and the nature of crime and its changes (e.g., seriousness: escalation and de-escalation; versatility: increased and decreased diversification), can be explained as outcomes of stability and changes in the frequency and nature of the criminogenic interactions people encounter in their daily life.

\section{Coda-Towards a Mechanism-Based Approach to the Explanation and Prevention of People's Crime and Criminal Careers}

The DEA model of SAT is aimed at, within the framework of an adequate action theory and a mechanism-based explanatory approach, ${ }^{26}$ building upon and extending key

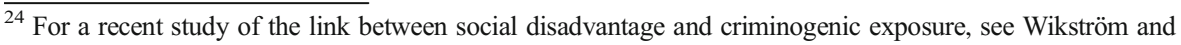
Treiber [41].

${ }^{25}$ For example, when a person who tends to see and choose violence as an action alternative in response to being disrespected confronts a setting in which such disrespect is shown to her or him.

${ }^{26}$ For a strong and convincing general argument regarding the advantages of mechanism-based explanatory approaches see Mario Bunge [5].
} 
insights from two poorly integrated but great traditions in the study of crime and its causes: the individual/ developmental and social ecological/environmental traditions.

In this paper, I have argued that to fully understand and explain criminal careers (and people's different pathways in crime) we first need to explicate what causes crime events. I have maintained that (1) crime events are an outcome of a perception-choice process triggered and guided by the interaction between people's crime propensities (based on their personal morals and ability to exercise self-control) and criminogenic exposure (based on the moral contexts of the temptations and provocations the settings they encounter provide), and, consequently, that (2) changes in people's crime involvement and its nature is a result of changes in their crime propensity and/or criminogenic exposure. Moreover, I have proposed that (3) the drivers of these changes are psychosocial processes of moral education and cognitive nurturing (affecting people's crime propensity) and processes of social and self-selection, (affecting people's exposure to criminogenic settings). Finally, I have insisted that (4) these processes are context dependent as regards their content and efficacy.

Against this background, I suggest that DLC criminology should aim at making a shift towards a more mechanism-based approach to the understanding and explanation of criminal careers (and pathways in crime). I further suggest that devising effective and lasting prevention policy and practises would benefit from a focus on developing integrated programs and interventions that is aimed at influencing the proposed basic drivers of criminal careers; the crime relevant aspects of processes of moral education, cognitive nurturing and social and self-selection (e.g. [42]).

The basic assumptions of the DEA model of SAT has been tested and supported in research from the UK prospective longitudinal Peterborough Adolescent and Young Adult Developmental Study (PADS+), a study that was especially designed to test core propositions of SAT and its DEA model (see, [47]).

Funding Information The research for this paper was funded by a grant from the ESRC (grant No ES/ K010646/1) and a grant from the Dawes trust.

Open Access This article is distributed under the terms of the Creative Commons Attribution 4.0 International License (http://creativecommons.org/licenses/by/4.0/), which permits unrestricted use, distribution, and reproduction in any medium, provided you give appropriate credit to the original author(s) and the source, provide a link to the Creative Commons license, and indicate if changes were made.

\section{References}

1. Bloom, B. S. (1964). Stability and change in human characteristics. New York: John Wiley.

2. Blumstein, A., Cohen, J., Roth, J. A., \& Visher, C. A. (1986). Criminal careers and career criminals (Vol. 1). Washington, D.C.: National Academy Press.

3. Bottoms, A. E. (2013). Learning from Odysseus: self-applied situational crime prevention as an aid to compliance. In P. Ugwudike \& P. Raynor (Eds.), What works in offender compliance. New York: Palgrave Macmillan.

4. Bronfenbrenner, U. (1979). The ecology of human development. Cambridge: Harvard University Press.

5. Bunge, M. (2004). How does it work? The search for explanatory mechanisms. Philosophy of the Social Sciences, 34, 182-210.

6. Chmura Kraemer, H., Kraemer Lowe, K., \& Kupfer, D. J. (2005). To your health: how to understand what research tells us about risk. Oxford: Oxford University Press. 
7. Cullen, F. (2011). Beyond adolescence-limited criminology: choosing our future. Criminology, 49, 287329.

8. Evans, G. W., Dongping, L., \& Whipple, S. (2013). Cumulative risk and child development. Psychological Bulletin, 139, 1342-1396.

9. Farrington, D. P. (2000). Explaining and preventing crime: the globalization of knowledge: the American Society of Criminology 1999 Presidential Address. Criminology, 38, 1-24.

10. Farrington, D. P. (2003). Developmental and life-course criminology: key theoretical and empirical issues. The 2002 Sutherland Award Address. Criminology, 41, 221-225.

11. Farrington, D. P., \& Wikström, P.-O. (1993). Criminal careers in London and Stockholm: a cross-national comparative study. In E. Weitekamp \& H.-J. Kerner (Eds.), Cross-national and longitudinal research on human development and criminal behavior. Dordrecht: Kluwer.

12. Farrington, D. P., Kazemian, L., \& Piquero, A. (2019). Conclusions and implications for developmental and life- course criminology. In D. P. Farrington, L. Kazemian, \& A. Piquero (Eds.), The Oxford handbook of developmental and life-course criminology. Oxford: Oxford University Press.

13. Jennings, W. G., \& Reingle, J. M. (2012). On the number and shape of developmental/life-course violence, aggression, and delinquency trajectories: a state-of-the-art review. Journal of Criminal Justice, 40, 472-489.

14. Jennings, W. G., Loeber, R., Pardini, D. A., Piquero, A. R., \& Farrington, D. P. (2016). Offending from childhood to young adulthood. Recent results from the Pittsburgh Youth Study. New York: Springer.

15. LeBlanc, M., \& Frechette, M. (1989). Male criminal activity from childhood through youth. Multilevel and developmental perspectives. New York: Springer verlag.

16. LeBlanc, M., \& Loeber, R. (1998). Developmental criminology updated. Crime and justice 23:115-198. Chicago: University of Chicago Press.

17. Loeber, R. (1990). Development and risk factors of juvenile antisocial behavior and delinquency. Clinical Psychology Review, 10, 1-41.

18. Loeber, R. (1991). Questions and advances in the study of developmental pathways. In D. Cicchetti \& S. Toth (Eds.), Rochester symposium on developmental psychopathology III. Rochester: Rochester University Press.

19. Loeber, R., \& LeBlanc, M. (1990). Toward a developmental criminology. Crime and justice 12:375-473. Chicago: University of Chicago Press.

20. Loeber, R., \& Wikström, P.-O. (1993). Individual pathways to crime in different types of neighborhoods. In D. P. Farrington, R. J. Sampson, \& P.-O. Wikström (Eds.), Integrating individual and ecological aspects of crime. Stockholm: Allmänna Förlaget.

21. Loeber, R., Wung, P., Keenan, K., \& Giroux, B. (1993). Developmental pathways in disruptive child behavior. Development and Psychopathology, 5, 103-133.

22. Loeber, R., Farrington, D. P., Stouthamer-Loeber, M., Moffitt, T. E., Caspi, A., Raskin, W. H., Wei, E. H., \& Beyers, J. M. (2003). The development of male offending. key findings from fourteen years of the Pittsburgh Youth Study. In T. Thornberry \& M. Krohn (Eds.), Tacking stock of delinquency. An overview of findings from contemporary longitudinal studies. New York: Kluwer Academic/Plenum Publishers.

23. Moffitt, T. E. (1993). Adolescence-limited and life-course-persistent antisocial behaviour: a developmental taxonomy. Psychological Review, 100, 674-701.

24. Moffitt, T. E. (2018). Male antisocial behavior in adolescence and beyond. Nature Human Behaviour, 2, $177-186$.

25. Morizot, J., \& Kazemian, L. (2015). Introduction: Understanding criminal and antisocial behavior within a developmental and multidisciplinary perspective. In J. Morizot \& L. Kasemian (Eds.), The development of criminal and antisocial behavior. New York: Springer.

26. Murray, J., \& Farrington, D. P. (2010). Risk factors for conduct disorders and delinquency: key findings from longitudinal studies. Canadian Journal of Psychiatry, 55, 633-642.

27. Murray, J., Farrington, D. P., \& Eisner, M. (2009). Drawing conclusions about causes from systematic reviews of risk factors: the Cambridge quality checklists. Journal of Experimental Criminology, 5, 1-23.

28. Nagin, D. S. (2005). Group-based modeling of development. Cambridge: Harvard University Press.

29. Piquero, A. R., Farrington, D. P., \& Blumstein, A. (2007). Key issues in criminal career research. New analysis of the Cambridge study in delinquent development. Cambridge: Cambridge University Press.

30. Sampson, R. J., \& Laub, J. H. (2003). Life-course desisters? Trajectories of crime among delinquent boys followed to age 70. Criminology, 41, 301-339.

31. Stouthamer-Loeber, M., Loeber, R., Wei, E., Farrington, D. P., \& Wikström, P.-O. (2002). Risk and promotive effects in the explanation of persistent serious delinquency in boys. Journal of Consulting and Clinical Psychology, 70, 111-123. 
32. Wikström, P.-O. (1987). Patterns of Crime in A Birth Cohort (project metropolitan. Report no. 24). Stockholm: University of Stockholm, Department of Sociology.

33. Wikström, P.-O. (1990). Age and crime in a Stockholm cohort. Journal of Quantitative Criminology, 6, 61-84.

34. Wikström, P.-O. (2005). The social origins of pathways in crime. towards a developmental ecological action theory of crime involvement and its changes. In D. P. Farrington (Ed.), Integrated developmental and life-course theories of offending. Advances in criminological theory. New Brunswick: Transaction.

35. Wikström, P.-O. (2006). Individuals, settings and acts of crime. Situational mechanisms and the explanation of crime. In P.-O. Wikström \& J. Sampson Robert (Eds.), The explanation of crime: context, mechanisms and development. Cambridge: Cambridge University Press.

36. Wikström, P.-O. (2010). Explaining crime as moral action. In S. Hitlin \& S. Vaysey (Eds.), Handbook of the sociology of morality. New York: Springer verlag.

37. Wikström, P.-O. (2011). Does everything matter? Addressing the problem of causation and explanation in the study of crime. In J. M. McGloin, C. J. Sullivan, \& L. W. Kennedy (Eds.), When crime appears: the role of emergence. London: Routledge.

38. Wikström, P.-O. (2017). Character, circumstances, and the causes of crime. In A. Liebling, S. Maruna, \& L. McAra (Eds.), The Oxford handbook of criminology. Oxford: Oxford University Press.

39. Wikström, P.-O., \& Treiber, K. (2009). What drives persistent offending. The neglected and unexplored role of the social environment. In J. Savage (Ed.), The development of persistent criminality. Oxford: Oxford University Press.

40. Wikström, P.-O., \& Treiber, K. (2015). Situational theory. The importance of interactions and action mechanisms. In A. Piquero (Ed.), The handbook of criminological theory. Chicester: Wiley Blackwell.

41. Wikström, P.-O., \& Treiber, K. (2016). Social Disadvantage and Crime. A Criminological Puzzle. American Behavioral Scientist, 60, 8.

42. Wikström, P.-O., \& Treiber, K. (2017). Beyond risk factors: an analytical approach to crime prevention. In B. Teasdale \& M. S. Bradley (Eds.), Preventing crime and violence, advances in prevention science. Volume 2. New York: Springer verlag.

43. Wikström, P.-O., \& Treiber, K. (2019). The dynamics of change. Criminogenic interactions and lifecourse patterns of crime. In D. P. Farrington, L. Kazemian, \& A. Piquero (Eds.), The Oxford handbook of developmental and life-course criminology. Oxford: Oxford University Press.

44. Wikström, P.-O., Ceccato, V., Hardie, B., \& Treiber, K. (2010). Activity fields and the dynamics of crime. Advancing knowledge about the role of the environment in crime causation. Journal of Quantitative Criminology, 26, 55-87.

45. Wikström, P.-O., Oberwittler, D., Treiber, K., \& Hardie, B. (2012). Breaking rules. The social and situational dynamics of young people's urban crime. Oxford: Oxford University Press.

46. Wikström, P.-O., Mann, R., \& Hardie, B. (2018). Young people's differential vulnerability to criminogenic exposure: Bridging the gap between people- and place-oriented approaches in the study of crime causation. European Journal of Criminology, 15, 10-31.

47. Wikström, P.-O., Treiber, K., \& Roman, G. (2019). Character, circumstances and criminal careers. Towards a dynamic developmental and life course criminology. Oxford: Oxford University Press.

48. Wolfgang, M., Figlio, R. M., \& Sellin, T. (1972). Delinquency in a birth cohort. Chicago: University of Chicago Press.

Publisher's Note Springer Nature remains neutral with regard to jurisdictional claims in published maps and institutional affiliations. 